\title{
Prolactin, maternal oestrogens, and breast development in the newborn
}

\author{
JOHN F McKIERNAN AND DAVID HULL
}

\author{
Department of Child Health, University Hospital, Queen's Medical Centre, Nottingham
}

SUMmARY To investigate the influence of maternal oestrogens on the fetal breast development, maternal urinary oestriol excretion, maternal plasma oestriol concentrations, and cord venous plasma oestradiol and oestriol concentrations were related to the size of the neonatal breast. A significant positive association between oestriol excretion and neonatal breast size was demonstrated, but the relationship was not strong and might be due to both measures having a positive relationship with birthweight. The infants' circulating concentrations of prolactin at birth and during the first weeks of life were also related to breast size. There was no cord venous-arterial difference in prolactin concentrations, and neither related to breast diameter. However there was a strong association between breast size and prolactin concentrations in mature infants aged between 5 and 7 days. In preterm infants breast tissue often develops after birth. Prolactin levels in preterm infants were higher between 2 and 6 weeks than they were in the first week of life. It would appear that the early development of the breast is influenced more by the infant's than the mother's endocrine activity.

The female breast reaches its maximal functional development during late pregnancy and the early puerperium when lactation is established. The factors which regulate the active proliferation of mammary tissue are not fully understood; however it is generally accepted that hormones secreted by the feto-placental unit play an important role. ${ }^{1}$ Oestrogens appear to be responsible for development of the breast duct systems, and progesterone for that of the lobules and alveoli. Animal and clinical studies have suggested that many other hormones may be concerned including prolactin, growth hormone, adrenal steroids, insulin, and human placental lactogen. Lactation as opposed to gland proliferation is inhibited during pregnancy by the high levels of circulating progesterone; and it is the progesterone withdrawal which occurs about the time of delivery in association with a continuing increase in prolactin levels, which initiates milk secretion.

The endocrine factors which influence the development of fetal breast tissue are less clearly understood. ${ }^{2}$ It is commonly assumed that the breast enlargement and secretion of milk which is present in many newborn infants is due to the 'side' effects of pregnancy hormones especially oestrogens. ${ }^{3}$ However, there are a number of considerations which indicate that the infant's own endocrine system may be more directly involved. ${ }^{4}$ For example, breast size at birth varies widely in apparently similar, healthy, mature, well-nourished infants, and in many babies breast nodules persist long after birth. Occasionally in otherwise normal newborn infants the breast nodule is impalpable but may develop later. Infants born before 34 weeks' gestation have little or no palpable breast tissue. In many, but not in all of these preterm infants the breast enlarges, becomes palpable, and secretes milk in the first months of postnatal life. Breast nodule size in light for gestational age newborn infants is appropriate for gestational age and yet oestriol excretion in maternal urine is generally lower than normal. ${ }^{5}$

In the first part of this study we have taken the opportunity provided by the current practice of monitoring levels of oestrogens in maternal urine and plasma in late pregnancy to assess fetal well being, to relate maternal urinary oestriol excretion and levels of oestriol in maternal plasma to the breast development of the infant at birth. It is appreciated that oestriol is a fairly weak biological oestrogen, ${ }^{6}$ but its production in pregnancy does reflect that of oestradiol, which is the most biologically potent oestrogen. We have also related breast size at birth to circulating levels of oestriol and oestradiol in umbilical venous plasma.

Of the various hormones secreted by the fetus, prolactin, from what we know of its behaviour, 
appears to be one which might play a major part in fetal breast tissue development and the release of milk from the neonatal breast. Prolactin levels in plasma are high at birth and in the first weeks of life. ${ }^{78}$ In some animals prolactin is an essential hormone for normal breast development ${ }^{9}$ it is not known if this is also true in man, though it is necessary for the initiation of lactation.

In the second part of this study the association between prolactin levels and breast nodule size was investigated in term and preterm infants.

\section{Subjects and methods}

The relationship between breast diameter and maternal 24-hour urinary oestriol excretion was studied in 87 newborn infants, mean birthweight $3.0 \mathrm{~kg}$ (range 1.7 to $4 \cdot 6$ ) and mean gestation 39 weeks (range 34 to 43 ). The urinary oestriol determinations had been made at, on average, 12 days (range 1 to 42) before delivery. Breast diameter was related to the oestriol concentration in maternal plasma measured, on average, 14 days (range 2 to 24) before delivery, in 38 newborn infants, mean birthweight $3 \cdot 2 \mathrm{~kg}$ (range $2 \cdot 2$ to $4 \cdot 6$ ) and mean gestation 38 weeks (range 34 to 41 ). The association between breast diameter and circulating concentrations of oestradiol and oestriol in umbilical cord venous plasma obtained at the time of delivery was examined in 20 newborn infants, mean birthweight $3.4 \mathrm{~kg}$ (range 2.9 to $4 \cdot 2$ ) and mean gestation 40 weeks (range 39 to 42). Breast diameter at birth was related to the prolactin level in umbilical venous plasma in 23 subjects. In 12 of these the prolactin level in cord arterial plasma at birth was estimated. The mean birthweight and gestational age of the infants was $3.4 \mathrm{~kg}$ (range 2.5 to $4 \cdot 2$ ) and 39 weeks (range 35 to 42) respectively. Seven were infants of diabetic mothers.

In all the above, diameter of the breast nodule was measured in the first 48 hours of life by one investigator using the method previously described. ${ }^{4}$ The prolactin level in heel-prick plasma of 12 infants, mean birthweight $2.9 \mathrm{~kg}$ (range $2 \cdot 1$ to $4 \cdot 3$ ) and mean gestation 39 weeks (range 33 to 42), on the sixth day of life was related to breast diameter at this time. All the above infants were healthy at birth.

Plasma prolactin levels were also measured in 25 infants aged 2 to 12 weeks who had been admitted to hospital with acute illnesses. None had central nervous system or endocrine disease or was receiving drugs known to affect prolactin secretion, or was of low birthweight.

Serial estimations were made of prolactin levels in the plasma of 9 very low birthweight infants during the first 6 weeks of life. The mean birthweight and gestation of these subjects was $1.0 \mathrm{~kg}$ (range 0.8 to $1 \cdot 2$ ) and 28 weeks (range 25 to 30 ) respectively, and although acutely ill in the neonatal period, all survived.

Gestational age of each infant was calculated from the first day of the mother's last menstrual period and expressed in completed weeks. Infants were judged as either appropriate for gestational age or light for gestational age using the 10th centile on the charts of Thomson et al.10 The maternal 24-hour urinary collections were carried out either in hospital or at home but results were not included in the study if urine collection seemed incomplete, as suggested by low urine volume or low creatinine excretion.

Urinary oestriols were estimated by the method of Lever et al. ${ }^{11}$ Maternal plasma was assayed by the Amersham Kit technique for total plasma oestrogens. The oestrogen conjugates were hydrolysed with an enzyme and the oestrogens measured by radioimmunoassay, using ammonium sulphate to separate the bound and free fractions.

Oestradiol and oestriol concentrations in umbilical cord plasma were measured by radioimmunoassay after extraction into diethyl ether, and evaporation of that solvent. The labelled hormones were tritiated, separated with Dextran-coated charcoal, and the bound fraction then counted in the liquid scintillation counter. Blood samples were obtained at the time of routine screening or monitoring procedures either by venepuncture or heelprick. The plasma prolactin concentrations were estimated in two assays by a specific double antibody radioimmunoassay using the Biodata prolactin kit (Serono Laboratories, UK Ltd). In this system an antihuman prolactin antibody is used and inter- and intra-assay variation is claimed to be less than $5 \%$. As circulating levels of prolactin in the newborn infant are very high, 67 only very small volumes of plasma were required for radioimmunoassay. Plasmas were stored at $-20^{\circ} \mathrm{C}$ until assay.

\section{Results}

There was a positive correlation between maternal urinary oestriol excretion and the breast diameter of the newborn infant (Fig. 1). There was considerable variation however, and it was clear that higher levels of oestriol excretion ( $>120 \mu \mathrm{mol}$ per 24 hours) were not regularly associated with greater mean breast diameter in the infants. The level of oestriol in maternal plasma did not appear to correlate with newborn breast size although large breast nodules in infants $(>10 \mathrm{~mm})$ were not found in association with low maternal plasma oestriol (Fig. 2a). Neither did the breast diameters of the newborn infants correlate with circulating concentrations of oestradiol 


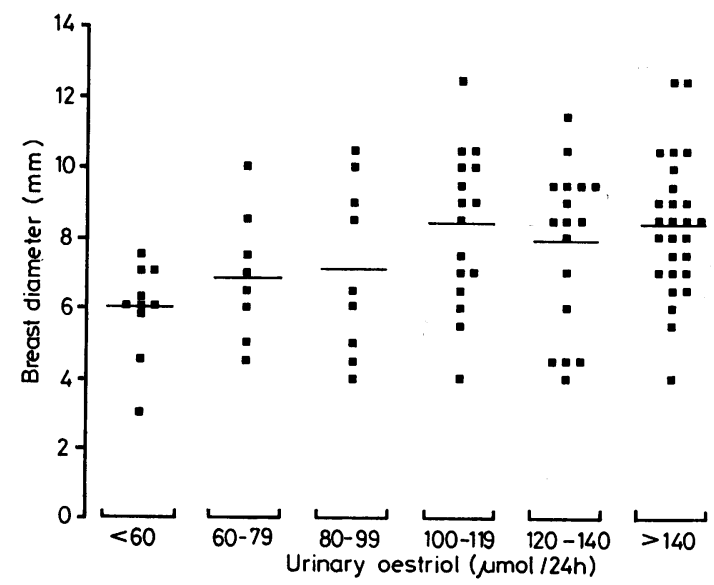

Fig. 1 Breast diamerer of newborn infants in relation to maternal 24-hour urinary oestriol excretion. Horizontal lines indicate means.

(Fig. 2b), oestriol (Fig. 2c), or prolactin in cord venous plasma at birth. On the sixth day of life however, when breast engorgement had begun in
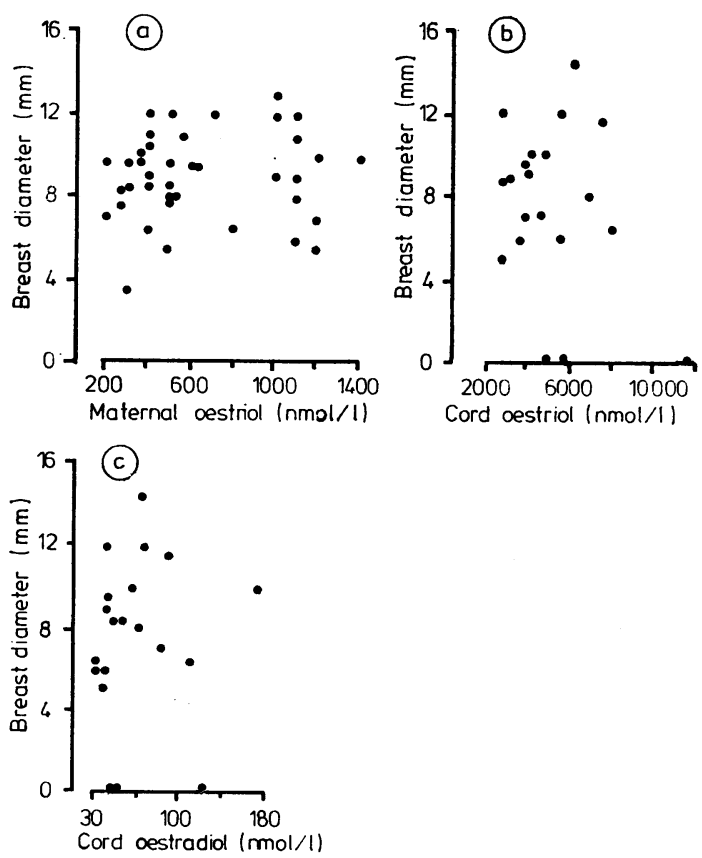

Fig. 2 Breast diameter in the newborn infants did not seem to be related with the concentrations of $(a)$, maternal plasma oestriols, (b) the umbilical cord plasma concentrations of oestriol, or (c) oestradiol.

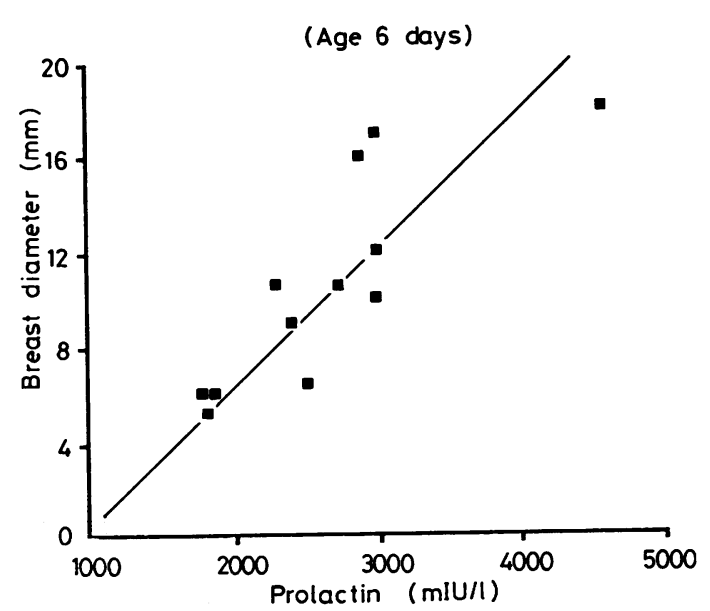

Fig. 3 Relationship between breast diameter and prolactin level in plasma on the sixth dav of life.

some infants, there was a positive correlation between breast size and prolactin concentrations (Fig. 3). Mean prolactin level in paired cord arterial and venous specimens was similar, the venous-arterial difference did not differ significantly from zero. Prolactin levels in the 7 infants of diabetic mothers were $4 \cdot 1,10 \cdot 1,7 \cdot 6,7 \cdot 3,3 \cdot 8,6 \cdot 5$, and $4 \cdot 1 \times 10^{3}$ $\mathrm{mIU} / \mathrm{l}$, all within the normal range.

Mean prolactin level in the infants of good birthweight declined sharply in the first 8 weeks of life and in only one infant did the level exceed 1000

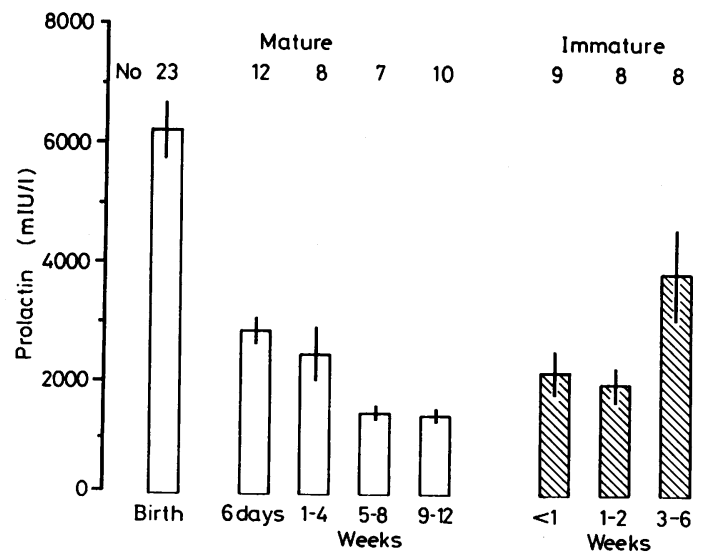

Fig. 4 Prolactin levels in plasma at birth and in the first 3 months of life in full size and very low birthweight newborn infants (means $\pm \mathrm{SE}$ ). 
$\mathrm{mIU} / 1$ after age 1 month. In contrast, the prolactin level in infants of very low birthweights increased from a mean of $2056 \mathrm{mIU} / \mathrm{l}$ in the first week of life to $3821 \mathrm{mIU} / \mathrm{l}$ at age 2 to 6 weeks (Fig. 4).

\section{Discussion}

The excretion of oestrogens in maternal urine in pregnancy increases with advancing gestation and is positively correlated with birthweight of the infant. ${ }^{5}$ The breast diameter of the newborn is also positively correlated with gestation and birthweight. ${ }^{4}$ It was not surprising therefore, that maternal oestrogen excretion and breast size of the newborn also correlated. However, the absence of a closer association in the subjects we have studied may be evidence that the feto-placental secretion of oestrogens, as reflected in maternal hormone levels, may have only a permissive effect on breast growth in the fetus and that higher oestrogen levels do not necessarily result in greater development. It is possible therefore, that the pronounced growth of the fetal breast in late gestation is to some extent independent of the maternal endocrine environment. The lack of correlation between hormone levels in umbilical cord plasma and newborn breast diameter may be due in part to acute changes in hormone concentrations occurring at the time of delivery.

Breast engorgement due to the spontaneous secretion of milk is common in mothers in the early puerperium and occurs even if breast feeding is not attempted, ${ }^{12}$ and we have recently shown that this is often present in newborn infants too. ${ }^{4}$ Hiba et al. ${ }^{13}$ have demonstrated that the onset of milk secretion after delivery in the mother and infant coincides with the decline in circulating sex steroid levels, in association with continuing increase in prolactin concentrations. The relationship we have found between the degree of breast engorgement in the newborn and the level of prolactin in plasma is further evidence that the immediate postnatal surge of activity in the newborn breast is mediated via the infant's secretion of prolactin and is not a passive effect of maternal hormones as is often suggested. Surprisingly, West and McNeilly ${ }^{12}$ were unable to find any clear endocrine basis for differences in degrees of breast engorgement experienced by nonbreast-feeding mothers.

Prolactin levels in the paired cord arterial and venous specimens were similar, which is consistent with the view that placental transfer of this hormone does not occur and is in agreement with the findings of Guyda and Friesen. 8

The results of this study have also confirmed previous reports that prolactin levels in newborn infants decline in the first weeks of life and reach normal childhood values by age 3 months. ${ }^{78}$ As levels of prolactin in fetal plasma increase 3-fold during the last trimester of pregnancy, ${ }^{7}$ it was not surprising that levels found in the first few days of life in the very immature infants were lower than values at birth or in the first week of life in more mature newborn infants. Of great interest however, was the absence of any decline in serial prolactin concentrations in the preterm infants during the first weeks of postnatal life. Hormone levels rose at this time. This finding is evidence that the pituitary glands of these infants continued to hypersecrete prolactin long after the withdrawal of feto-placental hormones. It is unlikely that the persisting increase in prolactin levels is a result of impaired metabolic clearance of prolactin. In a cross-sectional study of prolactin levels in early infancy, Guyda and Friesen ${ }^{8}$ also found that prolactin levels in preterm infants remained raised longer after birth than in term infants, although no details of the gestational ages of the subjects were provided. A sex difference was also found, levels of females being higher. Due to the small numbers, we are unable to comment on this aspect. Cornblath et al. ${ }^{14}$ have also reported that growth hormone levels in preterm infants were higher than in term infants in the first weeks of life. Interestingly, growth hormone and prolactin are structurally similar, and both are stress hormones. ${ }^{15}$ However, stress rarely produces pronounced increases in prolactin levels, and in late pregnancy in the mother prolactin concentrations are less influenced by stress than in the non-pregnant state. Although the effects of stress and illness on prolactin secretion in early life are not known, we feel that it is unlikely that these factors could have been responsible for the different patterns of prolactin secretion shown by plasma levels in preterm and term infants in the early months of postnatal life. Also, as the secretion of prolactin after birth in preterm infants continues at a high level it is possible that the hypersecretion in utero is also independent of the maternal endocrine environment.

Prolactin is an important mammotrophic hormone in some animals, ${ }^{9}$ and possibly in man also. For the initiation of lactation in mothers however, high levels of circulating prolactin are essential. We have previously shown that in preterm infants breast tissue may develop and become palpable after birth and that the secretion of milk may start some weeks after delivery, long after the disappearance of pregnancy hormones from the circulation. ${ }^{4}$ As the present study has shown that levels of prolactin appear to be physiologically increased at this time, it is likely that prolactin is involved in this postnatal phase of breast activity in preterm, as well as in more mature newborn infants. 
We thank Dr C Pillai, Mr C Selby, and Mr J King for technical assistance, and our colleages for allowing us to study patients under their care.

\section{References}

1 Vorherr H. The breast. London: Academic Press, 1974: 1-282.

2 Porter J C. Hormonal regulation of breast development and activity. J Invest Dermatol 1974; 63: 85-92.

3 Lubchenco L O. The high risk infant. Philadelphia: Saunders, 1976:1-294.

4 McKiernan J, Hull D. Breast development in the newborn. Arch Dis Child 1981; 56: 525-9.

5 Beling C. Estrogens. In: Fuchs F, Klopper A, eds. Endocrinology of pregnancy, second edition. Hagerstown: Harper \& Row, 1977: 76-98.

6 Bidlingmaier F, Knorr D. Oestrogens. Physiological and clinical aspects. In: Pediatric and adolescent endocrinology. Vol. 4. Basel: Karger, 1978: 1-6.

7 Aubert M L, Grumbach M M, Kaplan S L. The ontogenesis of human fetal hormones. III. Prolactin. J Clin Invest 1975 ; 56: 155-64.

8 Guyda H J, Friesen H G. Serum prolactin levels in humans from birth to adult life. Pediatr Res 1973; 7: 534-40.

9 Frantz A G. Prolactin. N Engl J Med 1978; 298: 201-7.
10 Thomson A M, Billewicz W Z, Hytten F E. The assessment of fetal growth. J Obstet Gynaecol Br Commonw 1968 ; 75 : 903-16.

11 Lever M, Powell J C, Peace S M. Improved estriol determination in a continuous flow system. Biochem Med $1973 ; 8$ : $188-98$.

12 West C P, McNeilly A S. Hormonal profiles in lactating and non-lactating women immediately after delivery and their relationship to breast engorgement. $\mathrm{Br} J$ Obstet Gynaecol 1979; 86: 501-6.

13 Hiba J, Del Pozo E, Genazzani A, et al. Hormonal mechanism of milk secretion in the newborn. $J$ Clin Endocrinol Metab 1977; 44: 973-6.

14 Cornblath M, Parker M L, Reisner S H, Forbes A E, Daughaday W H. Secretion and metabolism of growth hormone in premature and full-term infants. $J$ Clin Endocrinol Metab 1965; 25: 209-18.

15 Yen S S C. Physiology of human prolactin. In: Yen S S C, Jaffe R B, eds. Reproductive endocrinology, physiology, pathophysiology, and clinical management. Philadelphia: Saunders, 1978: 152-70.

Correspondence to Professor D Hull, Department of Child Health, Medical School, Queen's Medical Centre, Clifton Boulevard, Nottingham NG7 2UH.

Received 15 July 1980 